\title{
Project execution obstacles: a case of King Abdulaziz Airport in Saudi Arabia
}

\author{
Abdullah Al Hudhaif ${ }^{1}$ \\ Received: 18 May 2020/Accepted: 26 December 2020/Published online: 20 January 2021 \\ (C) Bharati Vidyapeeth's Institute of Computer Applications and Management 2021
}

\begin{abstract}
The purpose of this research is to examine the causes of delay in airport projects in general and the King Abdulaziz International Airport (KAIA) of Saudi Arabia in particular. The KAIA is the most strategic and busiest airport of Saudi Arabia, which transports millions of pilgrims from two hundred countries to perform Hajj and Umrah in Makkah. In general, more than $50 \%$ of construction projects fail on one more area. Our method of research is empirical based on the analysis of responses received from seventy-one respondents to our survey questions. We shall also synthesize literature that utilizes previous research and case studies on aviation and public project failures. We believe that this research will be valuable in ascertaining and mitigating direct causes for the numerous project delays in Kingdom of Saudi Arabia.
\end{abstract}

Keywords Airport - Construction · Projects - Project delays · Saudi Arabia $\cdot$ King Abdulaziz International Airport · Hajj · Umrah

\section{Introduction}

In this article, we shall explore the problems and obstacles contributing to extensive delays and over budgeting in the ongoing King Abdulaziz International Airport (KAIA) project and provide recommendations for effective and efficient project managements within the Kingdom of Saudi Arabia (KSA). For our research in this article we

Abdullah Al Hudhaif

Hudhaif1@gmail.com

1 Faculty of Economics and Administration, King Abdulaziz University, Jeddah, Saudi Arabia have used data from a survey of 71 respondents that were a mixture of manufactures, contractors, and suppliers that work in the project sectors.

According to Yamin [1], the construction industry in the KSA has witnessed a boom in the last decade to the tune of hundreds of billions of dollars. This is a result of growing rise in the demand for air travels. For example, as shown in Fig. 1, in the last year alone four and half billion passengers have used an aircraft for their travel in 2019 [2]. According to ATAG (2020) [3], flights in 2019 produced 915 million tons of $\mathrm{CO}_{2}$, directly and indirectly employed over 65 million people, and generated over 700 billion of dollars revenue to the GDP. There are more than one thousand and three hundred airlines which operate a fleet of about thirty-two thousand air operate a fleet of aircrafts utilizing just under four thousand airports managed by 170 air navigation service providers [3]. The industry is projected to grow to contribute more than one and a half trillion dollars by 2036 [3]. These and other statistics have encouraged many countries to expand their aviation and airport infrastructure.

Many projects in general and construction in particular confront many obstacles and suffer from extended delays resulting significant loss of money impacting the fiscal budgets, boarder security, health, education, and welfare programs. Some of the common causes of delays are poor planning, lack of proper documentation, inapt leadership, lack of communication, Inaccurate costing, and lack of moral ethics. Some of the most critical factors delays in construction projects, as identified in Ref. [4], are attributed to weather, poor site management, lack of planning, experience, poor communication, coordination, and lingering conflicts between stakeholders, shortages of material, equipment, and financial problems. A comprehensive 
Fig. 1 Air Travelers from 2004 to 2020

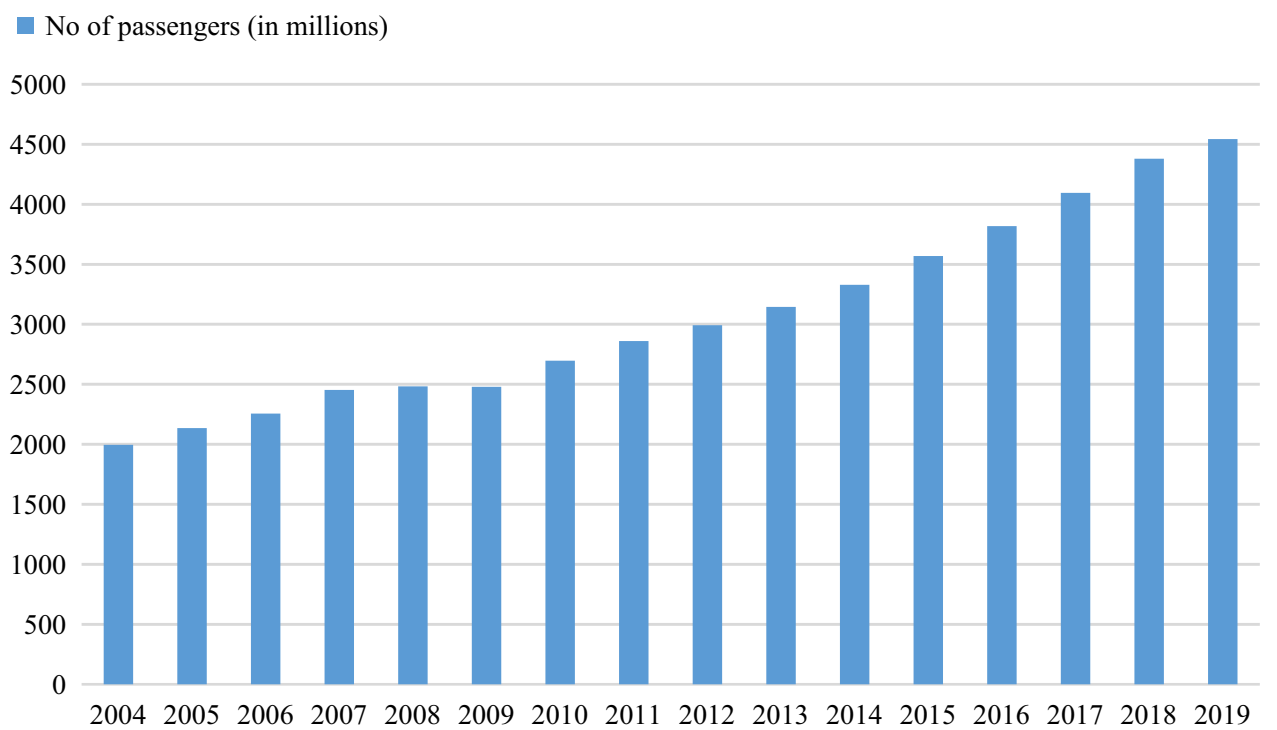

list of causes of delays in Saudi construction industry can be found in Ref. [5].

The tourism industry is one of the fastest growing industries throughout the world. According to Statista, the industry is having exponential growth in the Middle East with little less than two hundred million passengers in 2018. However, this growth has slowed down in 2019, and is expected to have dismal records in 2020 due to COVID19. However, if and when the COVID-19 was over, the tourism industry is expected to blossom once again. As the economy and the aviation industry are greatly expanding, KAIA [6] in Jeddah, is one of the two airports that have been expanding to accommodate the growing number of travelers to the KSA. It is estimated that the new terminal of the KAIA (Fig. 2) will serve millions of additional passengers collecting handsome contribution to the GDP.

One of the problems is that the construction of the expansion of KAIA was first delayed to 2017 [6, 7]. Currently, the first phase of the project is destined to be completed in 2020. There are numerous factors contributed to this delay. According to Ref. [7], the KSA had by 2014 already spent over $\$ 300$ billion and still had over $\$ 690$ billion worth of projects expected to be completed from 2006 to 2020. More information about failures and overspending can be gained from Refs. [8, 9]. In particular, in Ref. [9], there are details of insolvency of companies, slope in quality of construction, severe concerns for public safety, and general failure of the project. It remains to seen as to how much more delays would occur in completing these projects.

This paper has adopted an integrative approach combining both quantitative and qualitative approaches to evaluate the reason for the project delays in the newly built Saudi Arabian airports. This includes a descriptive case study approach by using data, and also data from industry and survey completed by the relevant project managers in Saudi Arabia.

Fig. 2 Outlook of new terminal of the KAIA

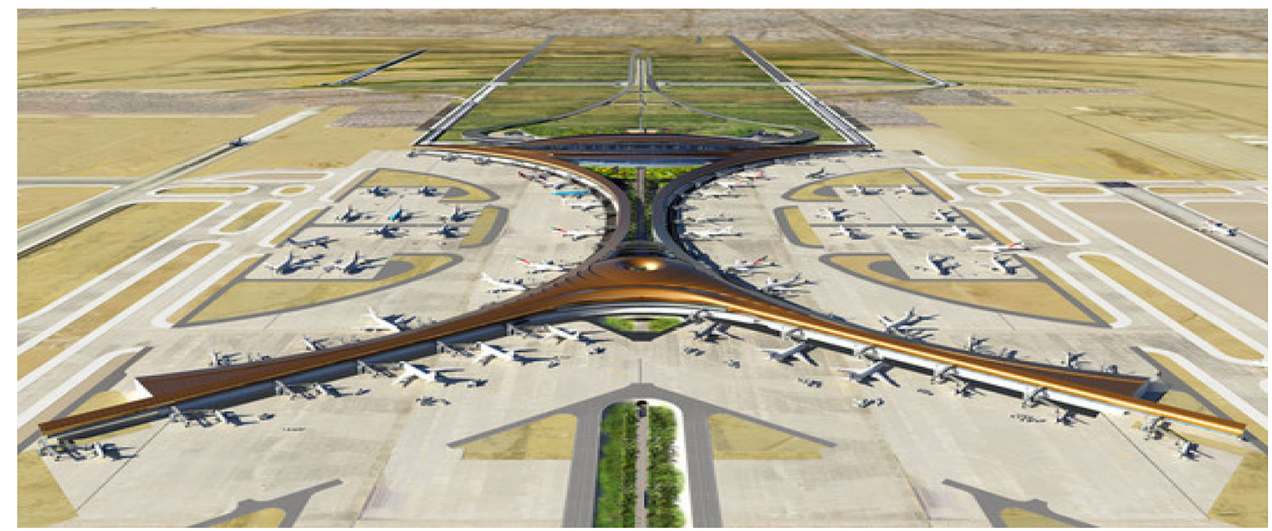




\section{Project management in Saudi Arabia}

The KSA accounts for the seventy percent of the Arabian Peninsula and has a population of over 33 million. The country is actively seeking to expand their airports to accommodate growing number of international and national travelers KAIA is the largest of airport projects, which was initially approved for 7.21 billion dollars. A well-known Saudi construction company, the Saudi awarded the contract to build it [6]. The project was supposed to have been completed in three years. However, it has been almost a decade, and the project is still not fully completed. In order to analyze the expansion project problems, we shall confine ourselves to the study of the Saudi Arabian cities and her projects.

The Kingdom of Saudi Arabia (KSA) has become a destination for international tourists since 2011, which is home to about thirty percent of expatriates working in different walks of life. Saudi Arabia is the 19th largest exporter, and 20th largest importer of electrical appliances, construction materials, plastics, petrochemicals, and many other materials, in the market, in which a balance of trade of over $\$ 6$ billion in revenue in favor of Saudi Arabia. The aviation industry in Saudi Arabia is looking at growth in both the public and private sectors. Makkah, a city at about $70 \mathrm{~km}$ from KAIA, houses Kaaba, which is the center of the annual pilgrimage known as the Hajj, and the ongoing pilgrimage known as the Umrah $[10,11]$. These pilgrimages attract about eight million foreign and ten million domestic pilgrims every year, more than eighty percent of the foreign pilgrims use KAIA for their travel.

\section{Literature review}

It is argued in Ref. [12] that coming into the contemporary world, way of life is enhanced and maintained by an inspiring assortment of construction, grand in its variety of function and form. As long as there are people on the planet, edifices will be built to serve them. In the Middle East, construction investments can vary enormously from country to country, and Saudi Arabia is the one of the most promising developing countries in the entire world and especially the Middle East.

In particular the airport industry in which has seen the biggest growth in the global market, as international travel has increased significantly. The Kingdom of Saudi Arabia since the oil boom, has experienced an enormous construction program, in which the 1980s saw KSA's government spend over $\$ 334$ billion on facility construction activities [13]. Researchers in Ref. [14] have noted that "during this economically prosperous period, mainly due to the growth in oil-derived revenue, many construction companies were established". After the oil industry, the construction industry in Saudi Arabia is the largest economic sector.

Reference [15] it is stated that current major projects were the Aldara Hospital costing over a hundred million dollars, the King Khalid International Airport, Terminal 5, costing about four hundred million dollars, a part of a larger expansion of the Airport to accommodate the increase passenger capacity. Currently in the airport industry, Saudi Arabia has over 20 current and future projects for expansions that are conducted to fill the annual increased capacity of airline passengers to the aviation industry. These includes expansion projects to almost each airport in Saudi Arabia, from Abha Regional Airport, Arar Domestic Airport, Al Jouf Domestic Airport, Prince Naif Bin Abdulaziz Airport, Prince Mohammed Bin Abdulaziz Airport, Al Baha Domestic Airport, King Abdulaziz Airport. These projects are estimated by this project own accounts to be over $\$ 20$ billion or more in contract worth, while tens of billions more in cost delays and budget overruns that will likely occur due to the history of the construction industry.

The problem however is the numerous project failures that have impacted Saudi Arabia's industry. There are no clear-cut reasons why these projects continue to fail. It is pointed out in Ref. [16] that there is a consensus about the importance of the project management practice. Success can be calculated through many changes that occur during the project life cycle which can provide stakeholders and project managers with a measure of success or failure. As commented in Ref. [17] that the "Iron Triangle" which includes quality, time, and cost, are not the only standards in assessing failure or success in projects. Project management encompasses the overall control, organization, and planning of a project from its beginning to its completion, in order to meet the needs and the wants of the client.

Thoroughly a project management function includes procurement, communication, human resources, quality, risk, cost, time, and project scope management. The overall integration of these eight functions and the managing of externalities is the ninth PM function [18]. The failures in the completion of many of Saudi Arabia's project are nothing short of an embarrassment, and a problem in which scholars use it as an example of poor project management. Other scholars have spoken on the importance of the project management in the construction, as detailed by Ref. [19] in their survey of over 180 different client organizations in questioning the factors of project success. The survey indicated that the 'project managers' managerial experience' is viable and can be as critical as the organizational and the project system factors. More research in 
the area of determining project success and why projects fail can be found in Ref. [20], in which it was concluded that in their multi-dimensional study the success of projects were based on project efficiency, in which financial success and client satisfaction tie into the question whether the project stayed on budget and on schedule. This helped in deciding project efficiency. What is clear that in their example was that many of Saudi Arabia's airport or construction projects have badly failed, and the blame can easily attribute to the poor management? As explained in Ref. [21], managers expect they will be able to identify, plan for, and influence all the variables and players in advance, but they obviously cannot do it all the time.

Looking at the current airport industry in Saudi Arabia, the private sector has played almost 50\% of the GDP with expectations to significantly increase as the country continues to receive investment from foreign entities [22]. The airline/aviation industry in Saudi Arabia is tied closely to the economic growth in the country, with a population of over 33 million people. It bolsters in the Middle East the largest domestic market. The kingdom (KSA) currently has four international airports and over twenty regional and domestic airports. Currently, the biggest expansion project is that of the KAIA. The Master Plan of the airport expansion shows that it will expanded in three phases, with the final phase set to be completed in 2017, in which the airport will be able to handle over 80 million passengers a year. The KAIA will have two new terminals for domestic and international passengers, as it will expand to an area of 670,000 square meters, the airport will accommodate the religious tourism that has flourished for travel during the Hajj, as it sits at the gateway to Medina and Mecca.

\section{Research methodology}

This paper uses an explorative approach in synthesizing literature that utilizes case studies, as the literature review serves a critical element to discuss the reasons for project delays in Kingdom of Saudi Arabia. Related literature has also been used in validating the synthesize information extracted from [23], who used a quantitative methodology in which they provided both a questionnaire and interviews used to collect data about ways to reduce delays and delay factors in manufacturing projects in Saudi Arabia. The methodology of this paper uses their data, as well as other case studies in providing valid information from the results of the surveys and questionnaires. The research questions explored are below:

- What are the causes for project delays in Saudi Arabia?

- What are the justifications for project costs?
- What are challenges of completing projects in Saudi Arabia?

These research questions are emphatically explored through the case studies and literature reviews, in which statistical information was performed on the quantitative data extracted from Ref. [23], who had surveyed five different organizations and over two data extracted from Ref. [23], who had surveyed five different organizations and over two hundred responses from the manufacturing industry in Saudi Arabia. This approach of qualitative research was chosen, as it provides the most comprehensive look into the reasons for project delays specifically in Saudi Arabia. The data was collected from the results of the survey and questionnaire of 71 respondents, a response rate of $52 \%$. The respondents where $33 \%$ contractors, $20 \%$ suppliers, and $47 \%$ manufacturers, with a mixture of junior level executives, and junior and senior level executives and staff. Based on the results, over half of the respondents have worked on up to eight projects throughout their careers, and over $30 \%$ worked on more than nine projects [23]. Data was obtained from information presented throughout their study, as well as additional information provided by their quantitative study on the reasons for project delays. In the survey below presents the top five reasons, out of several in which causes major problems. The survey looked at:

- Time Constraint issues.

- Lack of Planning in the Project Management Process.

- Changes in Project Scope and Decisions.

- Lack of Labor and Resources.

- Project Management's lack of Skills.

The survey instrument was designed using a Likert categorical scales that measured the respondents' attitudes towards the factors they feel are important, and consistent with findings from previous research. For the data analysis, since that data was collected from previous case studies, the data shown in Fig. 3 was analyzed using qualitative process, which involved the identification and examination of data, and interpretation of the textual and numeric. For analysis, we used pattern matching of the qualitative and quantitative data, which showed that out of the possible 52 factors in project delays, most outstanding reason was insufficient planning for materials, equipment, and manpower involved. Figure 3 shows the data that depicts the responses from various responders, as indicated Data Analysis Causes of Delays in Saudi Arabia Construction section. In this table, the respondents named their top five causes in which they believe that causes delays in projects, based on a scale from low to high. In each of the five categories, a high number of respondents believed that time, lack of planning, changes in scope, lack of labor and 
Fig. 3 Causes of Project Delays Responses
Causes of Project Delays

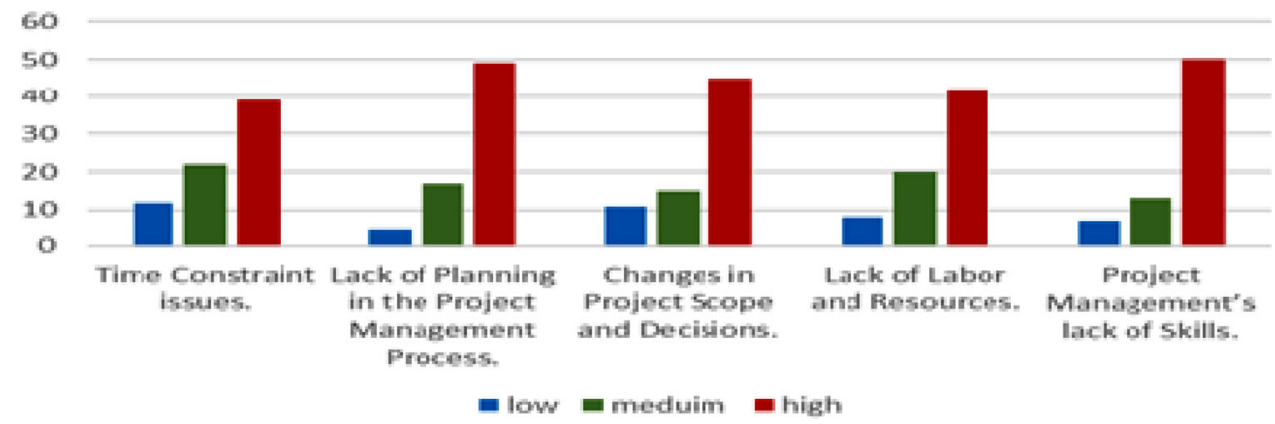

resources, and lack of project management skills, were the major causes of why projects delay or fail.

As indicated, Saudi Arabia is one of the fastest developing economies in the world. They have allocated hundreds of billions for planned constructions backed by the increasing oil revenues. With their increase in population, they have a huge demand for construction services, as this has also created a large demand in building materials and cement [15]. Foreign investments are high, and this has aided in their continued collection of awarding contract bids or the development of the non-infrastructure and infrastructure projects. The Kingdom's tourism is steadily growing, as it is anticipated that the religious pilgrimage will continue to bring in an influx of tourists to the Kingdom. In Ref. [23] it was highlighted that the Saudi Arabian government is executing new procedures and policies to further improve the economy of the nation through investment programs and sustained diversification.

\section{Data analysis and findings}

For the King Abdulaziz International Airport, as well as other large-scale projects in Saudi Arabia, a primary factor in their delay is outlined by Ref. [24] is notes as the failure of the Public Construction Sector to manage large construction projects confidently. Moreover, the Public Sector still lacks the capability and culture of a specialist Project Management Office (PMO) with the skills involved in guidance, documentation, and standardized metrics for managing, and executing the projects. Based on the compiled information used in data analysis, this paper can ascertain that the main source of challenges and difficulties in completing projects on time in Saudi Arabia. In looking at what it is means to have a delay in the project, it is significant to annotate that in terms of construction, delay is a relative term. It means that time overrun either past the date the parties approved upon for delivery of the project, or past the completion date specified in the contract; in both aspects, the delay is usually a costly factor. In simpler terms, a delay signifies an event or act, which lengthens the time necessary to complete or perform all works or part of the work under the contract. For construction projects in the Kingdom of Saudi Arabia, specifically, major projects such as King Abdulaziz International Airport in Jeddah.

- Meeting the daily target

- Ineffective supervision/management.

- Poor communication system and strategic planning.

- Engineering

- Complex and insufficient data for designs with goals not defined.

- Unskilled labor force including lack of experienced consultants, subcontractors, and contractors.

- Customer requirement of changes from the initial design.

- Equipment

- Problems in the calibration and certification of equipment.

- Insufficient tools and problems with installation.

- Unavailability of correct tools.

- Materials

- Defective, wrong, and low quality of supplied materials.

- Poor storage area and transit damage.

- Delay in procurement and material lead time.

- Time Management

- Wrong estimate of time completion.

- Management and labors leaving the work area for breaks and other at the same time.

- Reworks delay completion time.

- Risk Management

- Change in the design and scope of work.

- Dependency Supplier and Customer.

- Market risk and future planning. 
- Conflict between partners and/or owners.

- Safety

- Accidents on site due to risks when working with electrical equipment and high heights.

- Unavailability of work permits.

- Lack of awareness about safety leads to problems with safety standards and precautions.

- External Causes

- Probability of rainfall and sandstorms.

- Shortage of electricity.

- Finance

- Variation and Claims.

- Wrong estimation of materials and delay in vendor payments.

- Lack of budget.

- Employment Problems

- Lack of communication due to wrong management with the employees.

- Unskilled man force and managers, with frequent changes in manpower.

One of the key challenges for construction companies is completing the projects within the estimated budget, and on time, as delays in construction always amplifies project costs. The construction industry has added $30-40 \%$ of the growth in the economy for the Kingdom of Saudi Arabia. Currently the government of Saudi Arabia is capitalizing heavily into the construction industry. According to Central Department of Statistics and Information, the Saudi Arabian construction industry's contribution to GDP increased from $4.3 \%$ in 2011 to $4.8 \%$ in 2013 . The industry's value adds increased by $8.8 \%$, from SAR87.3 billion (US $\$ 23.3$ billion) in 2012 to SAR94.9 billion (US $\$ 25.3$ billion) in 2013 in real terms. The industry however, is plagued with problems with incompetency which has led to serious problems and risks such as:

- Delays in meeting duration of the project

- Rise in the project's total costs, that results in bankruptcy of companies

- Decline in quality of construction

- Severe concerns for public safety

- General failure of the project

Completion time is essentially important in construction. One of the central policies and objectives of any private or public sectors dealing with the performance of projects is to improve the performance of projects, from improving quality, decreasing of costs, and the completion of projects within their assigned time and budget constraints. The execution time is one of the measures of performance of any construction project, which are quality, costs, and time. The success of the project is measured by these methods which demonstrate the parties involved of the construction project the performance, in which mainly the contractor and the owner are looking at. All the parties involved seek a specified time for project completion, in the most economic means, with the necessary quality upheld. Time delays are the most widely held source for disputes in construction projects. In the past it was common to have delays in the completion time for construction projects. Today however, with the tight budgets, delays have become an especially important cost factor. Consequently, these delays mostly end up as construction claims. According to Ref. [25] the multiple construction projects have had significant negative impacts on the economic and social development of the country. They examined the critical factors that have contributed to the project delays in KSA and have concluded through their case study analysis of relevant literature, it its due to project management tools and techniques that minimize them. The lack of tools claims hinders the completion of projects in UAE and other countries, as well as causes delays in delivering projects.

The project's delivery time is an essential aspect to the owner regarding costs, additionally a concern for the contractors. The process of construction is imperiled to the stimulus of vastly unpredictable factors and shifting variables, which could result from various causes. These causes consist of the contractual relations, involvement of other parties, environmental conditions, the availability of resources, and the performance of construction parties. From the result of these sources, the construction projects are complicated by significant challenges which can cause delays in the project's completion time. These causes can be countered and in order to complete projects within budget and on time, the project managers must be willing to make changes to the overall construction management system in Saudi Arabia.

Security aspects in project management are critical. Some privacy, security and health issues are discussed in Ref. [25-29]. Further details of Saudi Arabian government projects are provided in Ref. [30].

\section{Conclusion}

The probability of projects encountered risks the proliferate projects risks are mostly inevitable, as well as there are sometimes avoidable. The problems persist that while during the last month of the Islamic calendar for five days there is a $690 \%$ increase in the average passenger traffic, but for the rest of year it the augmented capacity appears redundant for the airport expansion. There are large issues 
that play a critical role in the project delays in the airport expansion projects, as well as other construction projects. These includes administrative issues, drawing preparation and approval, rapid decision making and planning, lack of manpower, and lack of command and control.

While this research has also identified factors in delay in the sectors of: Meeting daily targets; Engineering; Equipment; Materials; Time Management; Risk Management; Safety; External Causes; Finance; and Employment Problems. Each of these factors have contributed to the negative image that Saudi Arabia has achieved in their project issues and delays that have cost the industry billons in additional costs to compensate the time and budget overruns. The lesson learned from conducting this research is that case studies are reliable and efficient approaches to exploratory studies that help in combining past and present information around the chosen topic. For Saudi Arabia, much information was available on their problems with delays, and how many of the problems identified throughout the decade, has continued to persist even with researchers that dwell in the country calling out the problems with the government. Additional problems identified are the large number of claims that inhibit the development and continued process of the construction, which contribute to the growing number of challenges that contractors, owners, and other management types face in project completions. For the King Abdulaziz International Airport, it has been plagued with the issues since the initial project expansion plan. They have faced challenges in lack of proper project management that has been contributed to the old way of thinking that has stunted international trust in the completion of large and major projects to the infrastructure in Saudi Arabia.

\section{The future research}

While examining the causes of delays in the Kingdom of Saudi Arabia's projects, it is important for future research to be dedicated to investigating the skills and experience that project managers require to have before they are commissioned on projects. In evaluating the skills and experience, it would be helpful in determining the success or failure prediction of the project.

\section{References}

1. Yamin M (2019) Information technologies of 21 st century and their impact on the society. Int J Inf Technol 11:759-766. https:// doi.org/10.1007/s41870-019-00355-1

2. Mazareanu E (Statista) Number of scheduled passengers boarded by the global airline industry from 2004 to 2020. [Online]. https:// www.statista.com/statistics/564717/airline-industry-passengertraffic-globally/ Accessed on 10 May 2020

3. Air Transport Action Group (ATAG 2020). Facts and Figures. [Online]. https://www.atag.org/facts-figures.html Accessed 10 May 2020

4. Durdyev S, Hosseini MR (2019) Causes of delays on construction projects: a comprehensive list. Int J Manag Proj Bus 13(1):20-46. https://doi.org/10.1108/IJMPB-09-2018-0178

5. Alsuliman JA (2019) Causes of delay in Saudi public construction projects. Alex Eng J 58(2):801-808. https://doi.org/10.1016/ j.aej.2019.07.002

6. King Abdulaziz International Airport. Information cite \& Guide. [Online]. http://www.jed-airport.com/ Accessed 10 May 2020

7. Ikediashi D, Ogulana S, Alotaibi A (2014) Analysis of project failure factors for infrastructure projects in Saudi Arabia: a multivariate approach. J Constr Dev Ctries 19(1):35-52

8. Albogamy A, Scott D, Dawood N (2012) Addressing construction delays in the Kingdom of Saudi Arabia. Int Proc Econ Dev Res 45:148

9. Allahaim FS, Liu L (2015) Causes of cost overruns on infrastructure projects in Saudi Arabia. Int $\mathbf{J}$ Collab Enterp $5(1-2): 32-57$

10. Yamin M (2019) Managing crowds with technology: cases of Hajj and Kumbh Mela. Int J Inf Technol 11:229-237. https://doi. org/10.1007/s41870-018-0266-1

11. Yamin M, Basahel AM, Abi Sen AA Managing Crowds with Wireless and Mobile Technologies. Hindawi. Wireless Communications and Mobile Computing, vol 2018, Article ID 7361597, 15 pages. https://doi.org/10.1155/2018/7361597

12. Clough Richard H, Sears Glenn A, Sears SK, Segner Robert O, Rounds Jerald L (2015) Contracting: a practical guide to company management, 8th edn. Wiley, Hoboken

13. Ahcom J (2004) A model for benchmarking contractors project management elements in Saudi Arabia. Master of Science thesis, KFUPM, Dhahran, Saudi Arabia. Available online. A model for benchmarking contractors project management elements in Saudi Arabia. Accessed 11 May 2020

14. Yamin M, Hudhaif Al, Abdullah A (2013) MIS in small industry: sanitary ware in Saudi Arabia. Int J Emerg Technol Adv Eng 4(11):490-494 (November 2014)

15. Amgad TH. Construction and projects in Saudi Arabia: overview. Practical Law (CONSTRUCTION AND PROJECTSO. Available (pdf) online. file:///C:/Users/ADMIN/Downloads/Saudi\%20Arabiapdf.pdf. Accessed 11 May 2020

16. Alexandrova M, Ivanova L. Critical success factors of project management: empirical evidence from projects supported by EU programmes. In: 9th International ASECU Conference on "Systematic Economic Crisis: Current Issues and Perspectives", Skopje, Macedonia. [Online]. http://www.asecu.gr/files/9th conf_files/alexandrova-and-ivanova.pdf. Retrieved 11 May 2020

17. Atkinson R (1999) Project management: cost, time and quality, two best guesses and a phenomenon, it's time to accept other success criteria. Int J Project Manage 17(6):337-342

18. Ling FYY, Low SP, Wang SQ, Lim HH (2009) Key project management practices affecting Singaporean firms' project performance in China. Int J Project Manage 27(1):59-71

19. Naoum SG, Fong D, Walker G (2004) Critical success factors of project management. In: CIB W107 and TG23 International Symposium on Globalization and Construction. Bangkok, Thailand 17-19 Nov 2004

20. Mir FA, Pinnington AH (2014) Exploring the value of project management: linking project management performance and project success. Int J Proj Manage 32(2):202-217

21. Matta NF, Ashkenas RN (2003) Why good projects fail anyway. Harv Bus Rev 81(9):109-116 
22. Annual Review 2015. IATA. [Online]. https://www.iata.org/con tentassets/c81222d96c9a4e0bb4ff6ced0126f0bb/iata-annualreview-2015.pdf. Accessed 11 May 2020

23. Alrashed I, Alrashed A, Taj S, Phillips M, Kantameneni K (2014) Risk assessments for construction projects in Saudi Arabia. Res J Manage Sci 3(7):1-6

24. Al-Harthi AA, Bageis AS, Ingirige B (2015) Preparation of Papers-Key External Causes of Poor Performance of Engineering and Technical Departments within Governmental Construction Projects in Saudi Arabia. Jeddah Saudi Arabia 13 (01)

25. Yamin M, Alsaawy Y, Alkhodre AB, Abi Sen AA (2019) An innovative method for preserving privacy in internet of things. Sensors 2019(19):3355. https://doi.org/10.3390/s19153355

26. Yamin M, Abi Sen AA (2018) Improving privacy and security of user data in location based services. Int $\mathrm{J}$ Amb Comput Intell 9(1):19-42. https://doi.org/10.4018/IJACI.2018010102
27. Yamin M (2018) IT applications in healthcare management: a survey. Int J Inf Technol 10(4):503-509. https://doi.org/10.1007/ s41870-018-0203-3

28. Sen AAA, Eassa FA, Jambi K, Yamin M (2018) Preserving privacy in internet of things - a survey. Int $\mathrm{J}$ Inf Technol 10(2):189-200. https://doi.org/10.1007/s41870-018-0113-4

29. Abi Sen AA, Eassa FB, Yamin M, Jambi K (2018) Double cache approach with wireless technology for preserving user privacy. Wirel Commun Mob Comput 2018:11. https://doi.org/10.1155/ 2018/4607464

30. Yamin M, Alharthi S (2020) Measuring impact of healthcare information systems in administration and operational management. Int $\mathrm{J}$ Inf Technol 12:767-774. https://doi.org/10.1007/ s41870-019-00329-3 